\title{
METHODS TO DETERMINE COMPLEX DEGREES OF MUTUAL ANISOTROPY FOR THE DIFFERENTIATION OF HEMORRHAGES IN THE HUMAN BRAIN SUBSTANCE RESULTING FROM TRAUMATIC AND NON-TRAUMATIC GENESIS Marta Garazdiuk $^{1}$, Viktor Bachynskiy ${ }^{2}$, Olena Nechytailo ${ }^{3}$, Oleksandr Garazdiuk ${ }^{4}$, Svitlana Malanchuk ${ }^{5}$
}

\begin{abstract}
An issue that is often debated in forensic traumatology is the differential diagnosis of hemorrhages into the human brain substance (HBS) of traumatic and non-traumatic genesis.

Objectives. This study aims to identify new criteria for objective forensic differentiation of hemorrhages of traumatic origin, cerebral infarction of ischemic and hemorrhagic genesis by using the method of complex degree of mutual anisotropy. For this study native sections of HBS from 125 corpses were used in the case of: death from coronary heart disease - 35 (28\%) of native sections (Group 1 - control); hemorrhages of traumatic genesis - 30 (24\%) sections (Group 2); ischemic cerebral infarction 30 (24\%) native sections(Group 3); and hemorrhages of non-traumatic genesis - 30 (24\%) native sections (Group 4).

Results. The statistical moments of the third and fourth orders, which characterize the asymmetry and excess of the complex degree of mutual anisotropy module size distributions, the strength of the method of polarization-correlation microscopy in the differentiation of the samples of the histological sections of the brain of control and experimental groups reached a good level $-87 \%-90 \%$

Conclusion. The method of complex degree of mutual anisotropy allows differentiating with great precision the genesis of hemorrhage into the substance of the brain.
\end{abstract}

UDC classification: 616.1, DOI: https://doi.org/10.12955/pmp.v1.92

Keywords: ischemic cerebral infarction; hemorrhages of traumatic and non-traumatic genesis, forensic medicine.

\section{Introduction}

Among the injuries, mechanical injuries occupy one of the leading places, and traumatic brain injuries are among them the most common (Konovalov, 2001). One of the debating issues in forensic traumatology is the differential diagnosis of hemorrhages into the human brain substance (HBS) of traumatic and non-traumatic genesis. Also, the social consequences of traumatic brain injury or ischemic injury should be considered, because such disabilities result in significant public expenditure and loss of human resources (Umbrasas, 2020; Zasler, 2019). Differential diagnosis of the cause of death (CD) from ischemic brain infarction (IBI), hemorrhages of traumatic (HTG), and non-traumatic (HNG) genesis helps to eliminate the suspicion of a violent cause of death (Pigolkina, et al., 2012; Leontiev, 2016).

Usually, the CD in such cases is established macroscopically and subsequently confirmed based on the histological conclusion (Khokhlov, 2010). However, forensic experts often have difficulty in the absence of pronounced external signs of trauma and with a prolonged period from the moment of injury to death. Also, the preparation of reagents, and subsequently histological preparations of HBS by appropriate staining methods, require from one-to-several days, which does not always satisfy the requirements of the judicial authorities (Khokhlov, 2010). Therefore, more and more attention is being paid to optical methods for the study of biological tissues using lasers which, by studying the lightscattering phenomena, make it possible to obtain reliable objective data on the dynamics of pre- and post-mortem changes of the studied tissues of the human body and with greater accuracy to diagnose CD because of hemorrhage into the substance of the brain (Bachinskiy, 2017).

At present, preliminary results of the polarization study of birefringence of optically thin specimens of pathologically-altered tissues are known, which were carried out in the laboratory of the Yuriy Fedkovych National University Institute of Physical, Technical Sciences, and Computer Science, which

\footnotetext{
${ }^{1}$ Higher State Educational Establishment of Ukraine "Bukovinian State Medical University", Department of Forensic Medicine and Medical Law, Chernivtsi, Ukraine, m.garazdiuk@gmail.com

${ }^{2}$ Higher State Educational Establishment of Ukraine "Bukovinian State Medical University", Department of Forensic Medicine and Medical Law, Chernivtsi, Ukraine, sudmed@bsmu.edu.ua

${ }^{3}$ Higher State Educational Establishment of Ukraine "Bukovinian State Medical University", Department of Anesthesiology and Reanimatology, Chernivtsi, Ukraine, olena.nechytailo@bsmu.edu.ua

${ }^{4}$ Higher State Educational Establishment of Ukraine "Bukovinian State Medical University", Internal Medicine and Infectious Diseases Department, Chernivtsi, Ukraine, olexandr.harazdiuk@ gmail.com

${ }^{5}$ Municipal Non-Commercial Enterprise "Clinical Maternity Hospital \# 1" of Chernivtsi City Council, s.malanchuk@gmail.com
} 
allows predicting the effective use of these methods for further verifications of hemorrhage into HBS (Ushenko, 2016; Ushenko, 2019).

\section{Purpose}

To identify new criteria for objective forensic differentiation of samples of depolarizing substance of the brain dead from ischemic heart disease (i) hemorrhages of traumatic origin; and (ii) cerebral infarction of ischemic and hemorrhagic genesis determined by using the polarization-correlation method of a complex degree of mutual anisotropy (CDMA) magnitude may be used to directly characterize the correlation consistency of optical anisotropy parameters of fibrillar networks of optically active protein complexes.

\section{Materials and methods}

This study uses native sections of HBS from 125 corpses in the case of death from coronary heart disease - 35 (28\%) of native sections (Group 1 - control); HTG- 30 (24\%) sections (Group 2), ICI - 30 (24\%) native sections (Group 3), HNG - 30 (24\%) native sections (Group 4).

For this study, the preparations were previously subjected to rapid freezing and histologic sections were made with a thickness of $20 \mu \mathrm{m}$. Subsequently, the samples were sent to the laboratory of the Yuriy Fedkovych Institute of Physical, Technical and Computer Sciences, where they were investigated using the CDMA method. The application method is described in these sources (Vanchulyak, 2019; Ushenko, 2016; Ushenko, 2019; Bachinskiy, 2017).

\section{Results and discussion.}

Figures 1-4 show the results of the polarization-correlation mapping of data and histograms of the magnitudes of the distributions of the CDMA module of histological sections of HBS for cases of:

- coronary heart disease (fig. 1 );

- HTG (fig.2);

- ICI (fig.3); and

- HNG (fig.4).

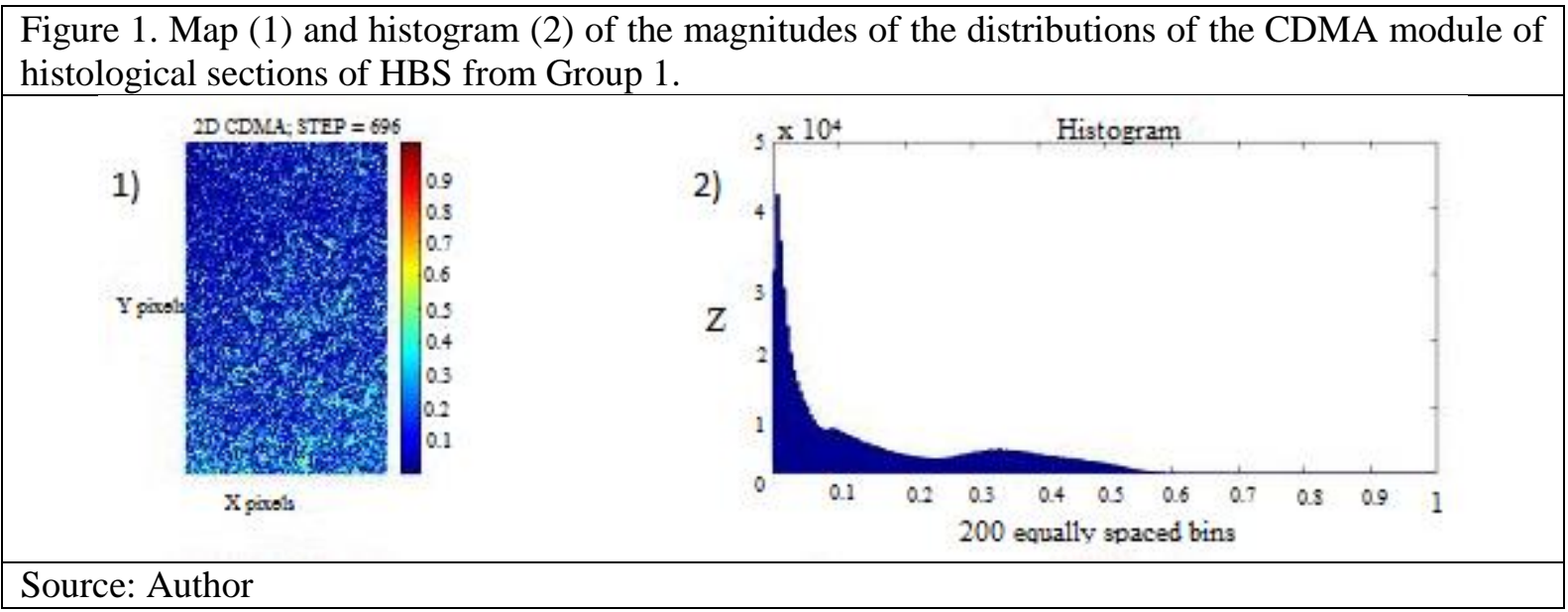

Figure 2. Map (1) and histogram (2) of the magnitudes of the distributions of the CDMA module of histological sections of HBS from Group 2

1)

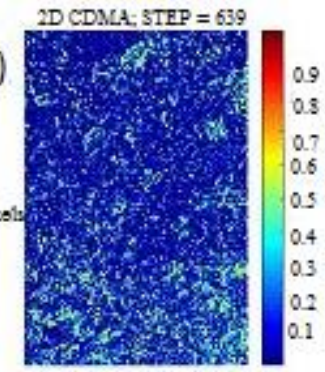

$x_{\text {pixsols }}$
2)

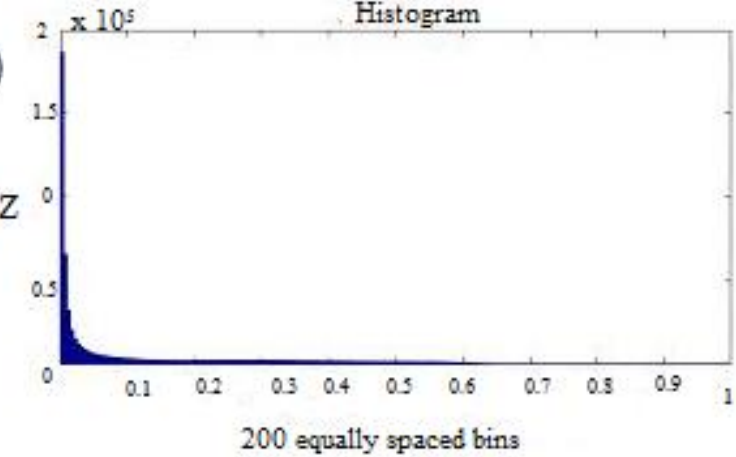

Source: Author 


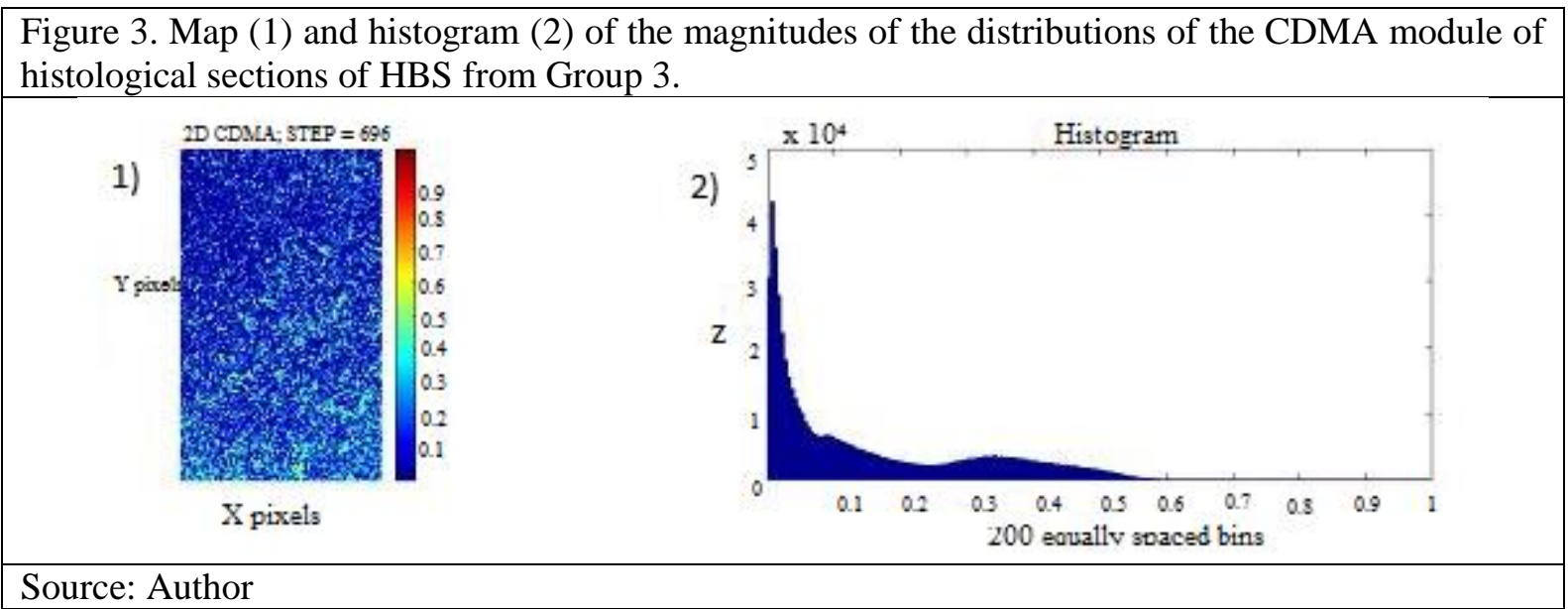

Figure 4. Map (1) and histogram (2) of the magnitudes of the distributions of the CDMA module of histological sections of HBS from Group 4.

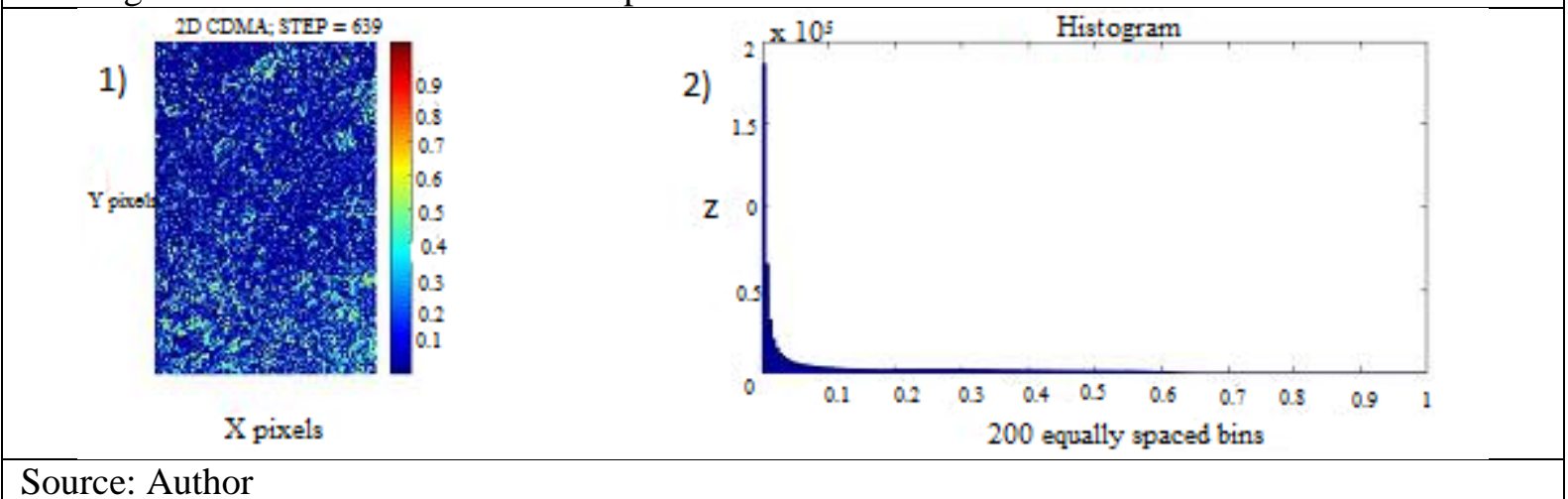

Comparative analysis of the results of the polarization-correlation mapping of manifestations of linear and circular birefringence of fibrillar networks of samples of HBS histological sections are revealed:

- coordinate heterogeneity of the maps of the CDMA module of the polycrystalline structure HBS histological sections of the dead from all groups (Figs. 1-4, fragments (1));

- the totality of the calculated histograms characterizing the CDMA module size distributions of the optically anisotropic samples of the control (Group 1) and experimental (Groups 2-4) groups has individual statistical parameters, such as dispersion of the scatter of random values; the significant asymmetry concerning the principal extremum; and the expressive sharpness (excess) of the peak of the distribution of the modulus of a given polarization-correlation parameter of the phase anisotropy of the polycrystalline component of the samples under study (Figs. 1-4, fragments (2));

- statistical structure of coordinate distributions of the CDMA module values of histological sections from the deceased in control Group 1 and all experimental Groups 2-4 (Figs. 1-4 fragments (2)) is individual within intergroup limits: Group 2 - Group 4 and Group 2 - Group 3.

Table 1 illustrates the magnitudes (averages and errors) of a set of statistical moments of the 1st - 4th orders, which characterize the coordinate distributions of the CDMA module values within representative samples of brain histological sections in the case of HTG, ICI, and HNG.

Evaluation of the obtained results revealed the diagnostic sensitivity of statistical moments of the first through the fourth orders (Table 1 for differentiation of optical anisotropy manifestations of samples of histological sections of the brain of the deceased of control Group 1 and experimental Groups 2-4 $\left(\rho_{1}<0,05\right)$. In addition, the possibility of polarization-correlation intergroup (experimental Groups 2-4 $\left(\rho_{3}<0,05\right) ; 2-3\left(\rho_{2}<0,05\right)$ and 3-4 $\left(\rho_{4}<0,05\right)$ statistical differentiation of the coordinate distributions CDMP module values of experimental representative samples of brain histological sections was revealed. 
Table 1. Statistical moments of the 1st - 4th orders, characterizing the distribution of the magnitude of the CDMA module of brain histological sections of Groups 1-4.

\begin{tabular}{|c|c|c|c|c|}
\hline Parameters & Group 1 & Group 2 & Group 3 & Group 4 \\
\hline$S M_{1}$ & $0.19 \pm 0.009$ & $0.13 \pm 0.006$ & $0.11 \pm 0.005$ & $0.09 \pm 0.004$ \\
\hline$\rho_{1}$ & & $\mathrm{p}<0.05$ & $\mathrm{p}<0.05$ & $\mathrm{p}<0.05$ \\
\hline$\rho_{2}$ & & \multicolumn{2}{|c|}{$p>0.05$} & $\mathrm{p}<0.05$ \\
\hline$\rho_{3}$ & & $p<0.05$ & \multicolumn{2}{|c|}{$p>0.05$} \\
\hline$\rho_{4}$ & & \multicolumn{3}{|c|}{$\mathrm{p}>0.05$} \\
\hline$S M_{2}$ & $0.16 \pm 0.007$ & $0.11 \pm 0.005$ & $0.1 \pm 0.0045$ & $0.09 \pm 0.004$ \\
\hline$\rho_{1}$ & & $\mathrm{p}<0.05$ & $\mathrm{p}<0.05$ & $\mathrm{p}<0.05$ \\
\hline$\rho_{2}$ & & \multicolumn{2}{|c|}{$p>0.05$} & $\mathrm{p}<0.05$ \\
\hline$\rho_{3}$ & & $\mathrm{p}>0.05$ & \multicolumn{2}{|c|}{$\mathrm{p}>0.05$} \\
\hline$\rho_{4}$ & & \multicolumn{3}{|c|}{$p>0.05$} \\
\hline $\mathrm{SM}_{3}$ & $0.87 \pm 0.041$ & $1.12 \pm 0.049$ & $1.31 \pm 0.058$ & $1.42 \pm 0.067$ \\
\hline$\rho_{1}$ & & $\mathrm{p}<0.05$ & $\mathrm{p}<0.05$ & $\mathrm{p}<0.05$ \\
\hline$\rho_{2}$ & & \multicolumn{2}{|c|}{$\mathrm{p}<0.05$} & $\mathrm{p}<0.05$ \\
\hline$\rho_{3}$ & & $\mathrm{p}<0.05$ & \multicolumn{2}{|c|}{$\mathrm{p}<0.05$} \\
\hline$\rho_{4}$ & & \multicolumn{3}{|c|}{$\mathrm{p}<0.05$} \\
\hline $\mathrm{SM}_{4}$ & $1.33 \pm 0.068$ & $1.58 \pm 0.047$ & $1.96 \pm 0.079$ & $1.71 \pm 0.063$ \\
\hline$\rho_{1}$ & & $\mathrm{p}<0.05$ & $\mathrm{p}<0.05$ & $\mathrm{p}<0.05$ \\
\hline$\rho_{2}$ & & \multicolumn{2}{|c|}{$\mathrm{p}<0.05$} & $\mathrm{p}<0.05$ \\
\hline$\rho_{3}$ & & $\mathrm{p}<0.05$ & \multicolumn{2}{|c|}{$\mathrm{p}<0.05$} \\
\hline$\rho_{4}$ & & \multicolumn{3}{|c|}{$\mathrm{p}<0.05$} \\
\hline
\end{tabular}

Source: Author

Operational characteristics of the method of statistical analysis of maps of the CDMA module of brain histological sections.

For a set of statistical parameters (statistical moments 1-4 orders of magnitude) that characterize the coordinate distributions of the CDMA module values of brain histologic sections from all groups, it is possible to calculate the values of operational characteristics (sensitivity $\mathrm{Se}, \%$, specificity $\mathrm{Sp}, \%$ and balanced accuracy Ac, \%) (see Table 2).

It is revealed that for the statistical moments of the third and fourth orders, which characterize the asymmetry and excess of the CDMA module values distributions, the strength of the method of polarization-correlation microscopy in the differentiation of the samples of the brain histological sections of the control group (ischemic heart disease), and experimental groups (ICI, HNG, and HTG) reaches a good level $-87 \%-90 \%$.

In parallel, a satisfactory level (79\%-85\%) of the diagnostic efficiency of intergroup differentiation of brain samples was established (experimental Groups 2-4; 2-3 and 3-4).

\section{Conclusions}

It was revealed that for the statistical moments of the third and fourth orders, which characterize the asymmetry and excess of the complex degree of mutual anisotropy module values distributions, the strength of the method of polarization-correlation microscopy in the differentiation of the samples of the brain histological sections of the control group (ischemic heart disease) and experimental groups (ischemic cerebral infarction; hemorrhages of traumatic and non-traumatic genesis) reaches a good level $-87 \%-90 \%$.

This result indicates that the complex degree of mutual anisotropy method allows differentiating the genesis of hemorrhage into brain tissue with high accuracy.

The methodology used to obtain these results may serve as standard procedures to conduct a complex investigation of possibilities and efficiency of application of methods of polarization-correlation microscopy in differential diagnostics of prescription of hemorrhage formation of traumatic genesis, cerebral infarction of ischemic, and hemorrhagic genesis. 
CBU INTERNATIONAL CONFERENCE ON INNOVATIONS IN SCIENCE AND EDUCATION 2020 (MEDICINE AND PHARMACY)

\begin{tabular}{|c|c|c|c|}
\hline \multicolumn{4}{|c|}{ Groups $1-2+3+4$} \\
\hline Parameters & Sensitivity, $\mathrm{Se}, \%$ & Specificity, $S p, \%$ & Accuracy, $A c, \%$ \\
\hline \multirow{2}{*}{$S M_{1}$} & $a=95, b=30$ & $\mathrm{c}=94, \mathrm{~d}=31$ & $\mathrm{n}=125$ \\
\hline & 76 & 75 & 75.5 \\
\hline \multirow[t]{2}{*}{$S M_{2}$} & $a=103, b=22$ & $c=100, d=25$ & $\mathrm{n}=125$ \\
\hline & 82 & 80 & 81 \\
\hline \multirow[t]{2}{*}{$\mathrm{SM}_{3}$} & $a=113, b=12$ & $c=109, d=16$ & $\mathrm{n}=125$ \\
\hline & 90 & 87 & 88.5 \\
\hline \multirow[t]{2}{*}{$\mathrm{SM}_{4}$} & $a=113, b=12$ & $\mathrm{c}=110, \mathrm{~d}=15$ & $\mathrm{n}=125$ \\
\hline & 90 & 88 & 89 \\
\hline \multicolumn{4}{|c|}{ Groups 2-3 } \\
\hline Parameters & Sensitivity, $\mathrm{Se}, \%$ & Specificity, $S p, \mathrm{~b} \%$ & Accuracy, $A c, \%$ \\
\hline \multirow[t]{2}{*}{$S M_{l}$} & $a=90, b=35$ & $\mathrm{c}=85, \mathrm{~d}=40$ & $\mathrm{n}=125$ \\
\hline & 72 & 68 & $\mathbf{7 0}$ \\
\hline \multirow[t]{2}{*}{$S M_{2}$} & $a=93, b=32$ & $\mathrm{c}=88, \mathrm{~d}=37$ & $\mathrm{n}=125$ \\
\hline & 74 & $\mathbf{7 0}$ & 72 \\
\hline \multirow[t]{2}{*}{$\mathrm{SM}_{3}$} & $a=106, b=19$ & $c=101, d=24$ & $\mathrm{n}=125$ \\
\hline & 85 & 81 & 83 \\
\hline \multirow[t]{2}{*}{$\mathrm{SM}_{4}$} & $a=113, b=12$ & $c=103, d=22$ & $\mathrm{n}=125$ \\
\hline & 85 & 82 & 83.5 \\
\hline \multicolumn{4}{|c|}{ Groups 2-4 } \\
\hline Parameters & Sensitivity, $\mathrm{Se}, \%$ & Specificity, $S p, \%$ & Accuracy, $A c, \%$ \\
\hline \multirow[t]{2}{*}{$S M_{1}$} & $a=91, b=34$ & $\mathrm{c}=88, \mathrm{~d}=37$ & $\mathrm{n}=125$ \\
\hline & 73 & $\mathbf{7 0}$ & $\mathbf{7 1 , 5}$ \\
\hline \multirow[t]{2}{*}{$S M_{2}$} & $a=96, b=29$ & $\mathrm{c}=94, \mathrm{~d}=31$ & $\mathrm{n}=125$ \\
\hline & 77 & 75 & 76 \\
\hline \multirow[t]{2}{*}{$\mathrm{SM}_{3}$} & $a=106, b=19$ & $c=101, d=24$ & $\mathrm{n}=125$ \\
\hline & 85 & 81 & 83 \\
\hline \multirow[t]{2}{*}{$\mathrm{SM}_{4}$} & $a=106, b=19$ & $c=103, d=22$ & $\mathrm{n}=125$ \\
\hline & 85 & 82 & 83.5 \\
\hline \multicolumn{4}{|c|}{ Groups 3-4 } \\
\hline Parameters & Sensitivity, $\mathrm{Se}, \%$ & Specificity, $S p, \%$ & Accuracy, $A c, \%$ \\
\hline \multirow[t]{2}{*}{$S M_{1}$} & $\mathrm{a}=88, \mathrm{~b}=37$ & $\mathrm{c}=81, \mathrm{~d}=44$ & $\mathrm{n}=125$ \\
\hline & $\mathbf{7 0}$ & 65 & 67,5 \\
\hline \multirow[t]{2}{*}{$S M_{2}$} & $a=85, b=40$ & $\mathrm{c}=79, \mathrm{~d}=46$ & $\mathrm{n}=125$ \\
\hline & 68 & 63 & 65,5 \\
\hline \multirow[t]{2}{*}{$\mathrm{SM}_{3}$} & $a=103, b=22$ & $\mathrm{c}=99, \mathrm{~d}=26$ & $\mathrm{n}=125$ \\
\hline & 82 & 79 & 80.5 \\
\hline \multirow[t]{2}{*}{$\mathrm{SM}_{4}$} & $a=101, b=24$ & $\mathrm{c}=96, \mathrm{~d}=29$ & $\mathrm{n}=125$ \\
\hline & 81 & 77 & 79 \\
\hline
\end{tabular}

\section{References}

Bachinskiy, V., Boichuk, T., \&amp; Ushenko, A. (2017). Laser polarimetry of biological tissues and fluids. LAP LAMBERT Academic Publishing.

Khokhlov, V. V. (2010). Forensic Medicine: A Guide (3rd ed.). Smolensk.

Konovalov, A. N., Likhterman, L. B., \&amp; Potapova, A. A. (Eds.). (2001). Clinical Guide to Traumatic Brain Injury. Moscow: Antidor.

Leontiev, P. O. (2016). Radiation diagnosis of epi- and subdural hematomas is a set of forensic criteria for the prescription of their causes. Medicine Today and Tomorrow, 4, 96-102.

Pigolkina, E. Yu., Dorosheva, Zh. V., Sidorovich, Yu. V., \&amp; Bychkov, A. A. (2012). Modern aspects of forensic medical diagnostics of the craniocerebral injury. Forensic Medical Expertise, 55(1), 38-40.

Umbrasas, K. V. (2020). Traumatic Brain Injury, Working Memory, and Violent Crime in a Sample of U.S. Service Members Involved in the Military Justice System. Military Medicine, usaa013. doi: https://doi.org/10.1093/milmed/usaa013 Ushenko, A.G., Dubolazov, A.V., Ushenko, V.A., Ushenko, Yu.A., Pidkamin, L.Y., Soltys, I.V. ... Pavlyukovich, N. Mueller-matrix mapping of optically anisotropic fluorophores of molecular biological tissues in the diagnosis of death causes. 
(2016). Proceedings of SPIE, 9971, Applications of Digital Image Processing, XXXIX, 99712L. doi:https://doi.org/10.1117/12.2237662

Ushenko, V. A., Sdobnov, A. Yu., Mishalov, W. D., Dubolazov, A. V., Olar, O. V., Bachinskyi, V. T. ... Meglinski I. (2019). Biomedical applications of Jones-matrix tomography to polycrystalline films of biological fluids. Journal of Innovative Optical Health Sciences, 12(6), 1950017. doi: 10.1142/S1793545819500172

Vanchulyak, O., Ushenko, Y., Galochkin, O., Sakhnovskiy, M., Kovalchuk, M., Dovgun, A., Bodnar, G. (2019). Azimuthal fractalography of networks of biological crystals. Proceedings of SPIE, 11105, Novel Optical Systems, Methods, and Applications, XXII, 1110517. doi: https://doi.org/10.1117/12.2529337

Zasler, N. D., Bender, S. D. (2019). Validity Assessment in Traumatic Brain Injury Impairment and Disability Evaluations. Physical Medicine and Rehabilitation Clinics of North America, 30(3), 621-636. doi: 10.1016/j.pmr.2019.03.009 